\title{
Managing Intimate Partner Violence in the Emergency Department
}

\author{
Esther K. Choo, MD, MPH and \\ Department of Emergency Medicine, Warren Alpert Medical School of Brown University, \\ Providence, RI \\ Debra Houry, MD, MPH \\ Department of Emergency Medicine, Emory University School of Medicine, Atlanta, GA
}

\section{Introduction}

Intimate partner violence (IPV) is a pattern of assaultive or coercive behaviors, perpetrated by someone who was or is in an intimate relationship with the person. IPV includes injury, psychological abuse, forced social isolation, intimidation, threats, and stalking. Very few health conditions impact as many people as profoundly as IPV: in the United States, more than one third of women and one fourth of men will experience physical violence, threats and rape by a partner over their lifetimes. ${ }^{1}$

Major medical organizations, including the Joint Commission, the American College of Emergency Physicians (ACEP) ${ }^{2}$ and the US Preventive Services Task Force, ${ }^{3}$ have advocated for screening by healthcare providers at point of contact, and the Institute of Medicine (IOM) has recommended incorporating IPV screening as part of preventative care. ${ }^{4}$ However, in practice, screening rates are low, even after training initiatives and triage protocols, ${ }^{5}$ and providers demonstrate uncertainty around screening and counseling. ${ }^{6}$ The identification and management of IPV requires only a few, straightforward actions, but they must be done consistently and with sensitivity to the difficulty of disclosing abuse and the potentially complex needs of the individual being abused.

\section{Screening}

Despite the challenge of demonstrating improved patient-centered outcomes from ED screening, it can be done safely and effectively without endangering patients ${ }^{7}$ and has the potential to identify patients at future risk for violence. ${ }^{8} \mathrm{~A}$ sample of brief validated screening tools appropriate for use in the ED are available ${ }^{9-12}$ (Figure 1); complete information about screening instruments is available from the CDC (Figure 2). Suggested language to use during screening is shown in Figure 3, including informing patients about

(C) 2014 Published by the American College of Emergency Physicians.

Publisher's Disclaimer: This is a PDF file of an unedited manuscript that has been accepted for publication. As a service to our customers we are providing this early version of the manuscript. The manuscript will undergo copyediting, typesetting, and review of the resulting proof before it is published in its final citable form. Please note that during the production process errors may be discovered which could affect the content, and all legal disclaimers that apply to the journal pertain. 
the limits of confidentiality and using a brief normalizing statement (Figure 3). There are conflicting recommendations about whether healthcare organizations should provide universal or targeted screening: however, due to the high prevalence of IPV in the ED, and because screening, by definition, is looking for a condition before it is overtly symptomatic, we recommend screening every patient whenever possible. Doing so in a busy ED requires that screening support be built into the system, whether through standardized intake processes or electronic medical records (EMR).

Screening must be done in a setting and manner that facilitates divulging abuse. ${ }^{6,13}$ This includes: asking screening questions in a private place and without any visitors present; using respectful and non-judgmental tone of voice and body language; and having ready responses when screening reveals the presence of abuse. ${ }^{6,14}$ Screening is typically implemented by nurses, with positive screens resulting in prompt physician notification; however, physicians should also consider performing their own secondary screen, especially in high-risk patients, such as those with head, neck, and facial injuries, depressive symptoms, suicidal ideation, repeat visits, or substance use disorders. ${ }^{15}$ Training and system-level procedures are subject to attrition. ${ }^{5}$ Therefore, administrators should regularly review any protocol put into place for screening and intervention to ensure it is being followed, and staff must receive ongoing training to maintain their skills and knowledge.

Medical illness and altered mental status, whether through intoxication or other condition, may make screening on arrival difficult or impossible. Many patients will miss first-pass screening; unfortunately, often these patients are those at higher risk of IPV. ${ }^{16}$ Ideally, the EMR and nursing protocols should be designed to prompt providers to screen closer to the end of the ED visit for patients who miss triage / entry screening.

\section{Response to Identification of Partner Abuse}

Responding to a positive screen adequately involves a simple set of actions at the bedside. First, the screen must be followed with confirmation, which is simply allowing the patient to explain the abuse they are experiencing. This is elicited by an open-ended question (Figure 3). Importantly, providers must validate and legitimize the patient. ${ }^{17}$ Patients experiencing IPV are subject to controlling and coercive partner behaviors, and often experience isolation and shame, believing that they are to blame for the abuse. Validation statements ${ }^{17,18}$ (Figure 3) provide immediate affirmation that disclosing abuse was welcome and appropriate. The ED provider should seek to encourage and empower patients to speak to health care providers and to overcome any reluctance to seek help for their abuse, both during the current visit and in the future. Patients may be divulging abuse for the first time, and may experience it as emotional, embarrassing, and frightening.

\section{Addressing Immediate Safety Concerns}

Assessing the immediate safety concerns of the patient for themselves and for any children in the household will determine the next critical steps. ${ }^{19}$ Patients should be asked if they feel safe to leave the ED; a brief formal danger assessment tool may be used as a follow up to a positive screen to calculate risk of severe future IPV and may perform better than selfassessment of risk (see Figure 4). ${ }^{20}$ If the patient does not feel safe to go home, they will 
need to be linked to domestic violence agencies to seek alternative housing. ${ }^{21}$ Given the shortage of domestic violence shelter beds, patients may need to consider alternative housing through friends or family for the short term; some hospitals will admit a patient in danger of violent victimization who do not feel safe to go home and have no other options. Child protective services must be consulted if there is concern for the safety of children in the household.

Patients experiencing abuse should be offered the opportunity to receive assistance contacting law enforcement to make a report and initiate the process of obtaining a restrain orders. If they do not wish to initiate this process while in the ED, they should be given information on how to do so, and made aware that domestic violence agencies' services include navigating law enforcement and legal aid.

Laws on mandatory reporting of domestic violence by healthcare providers differ from state to state. Most states have some requirement to report domestic violence (or any other types of violence) in certain circumstances, such as when guns or other weapons are used. ${ }^{22}$ Individual state laws can be accessed through local police departments or online (see Figure 2). Child abuse and elder abuse, in contrast, must be reported; if these are revealed to coexist with partner violence, providers cannot assure confidentiality.

In the vast majority of cases, patients will be returning home, rather than to a shelter. Anticipating and understanding this, remaining supportive and encouraging, and avoiding responses of frustration, disbelief, or disapproval will ensure the patient does not feel judged or looked down upon, and may increase the possibility that they will seek help from health care providers in the future. It can take many attempts at leaving before someone leaves an abusive relationship permanently.

\section{Safety Behaviors}

Ideally, patients should be instructed in a variety of steps they can take to keep themselves and their children safe and to allow them to leave the home quickly in case violence should escalate (Figure 5). A brochure or card may help the provider review safety behaviors with the patient or create a personalized safety plan; however, the patient should be encouraged to learn more about safety behaviors with domestic violence agencies as an outpatient.

\section{Documentation}

Partner abuse or suspected partner abuse should be clearly documented so that future providers know to follow up on the issue. If injuries are present, these should be photographed and included in the patient chart, in case legal evidence is needed at a later time. ED providers should contact primary care providers, whenever possible, to ensure continuity of care around this issue, as it is likely to be a chronic, ongoing problem and can result in chronic medical conditions. 


\section{Referrals}

Patients experiencing IPV should receive, at the minimum, referrals to local or national domestic violence hotlines. General resources and links to local domestic violence agencies are available online (Figure 2). While all these sites have a "quick exit" button, patients need to be reminded that they must delete stored browsing histories.

Screening for associated high-risk conditions, including mental health problems ${ }^{23}$ and substance use, and asking about basic needs, such as primary care providers for the patient and their children and financial and housing support, can guide appropriate referrals to health care and other services. Although comprehensive services (including job training, legal aid, childcare, etc.) will also be addressed through domestic violence agencies, a simple resource like a handout with contact information for local services may help address the many barriers that can keep patients dependent on abusive relationship and thus with limited options for improving their safety and wellbeing. To ensure a patient's safety, these resources should not be labeled "domestic violence" but rather women's health issues, general social services, or other more general terms.

\section{Special Populations}

Women in heterosexual couples are not the only ones experiencing IPV; provider assumptions should not prevent screening of other groups of patients. IPV is as prevalent or more prevalent in male and female single sex couples as in heterosexual couples. ${ }^{1}$ Men are often assumed to be only perpetrators of IPV but also experience victimization and are at increased odds for mental and physical health sequelae of abuse. ${ }^{1,24}$ Domestic violence shelters are generally not available for men. However, most domestic violence agencies will provide counseling and other services for male survivors.

Women with undocumented or dependent immigration status are particularly vulnerable to partner abuse, given their social isolation and their financial, emotional and psychological dependence on their partner, traditional gender norms, and stresses around the process of acculturation. ${ }^{25,26}$ Cultural norms or fear of authorities may encourage women to not report IPV. Screening is critical for immigrant women, should be done privately and with assurance for confidentiality, and using, if possible, a culturally specific interpreter.

\section{Identifying Roles in the Emergency Department for Addressing IPV}

Who performs these functions varies widely by hospital and state. Counseling and referrals for patients experiencing partner violence may be a designated role for an ED nurse or social worker. In some areas, the local or regional domestic violence agency may have an on-call crisis team that will travel to any ED and provide in-person counseling, assist with safe housing, and provide active linkages to domestic violence agencies for follow up. In other cases, individual ED providers will be managing all aspects of care for abused patients. However, in all cases, ED providers will need to understand how to identify IPV and how to gain rapport with the patient so that they feel comfortable discussing abuse, be familiar with available resources, and know who to consult for further care and referrals. Physicians 
should take advantage of free online IPV training and patient resource materials (Figure 2) and IPV-related didactic instruction at national EM conferences.

\section{Conclusions}

IPV is common among ED patients. It is important to incorporate IPV screening into triage or as part of physician care, particularly for patients with high-risk presentations. ED care for patients experiencing partner abuse involves only a few steps, and many potential obstacles to IPV management have straightforward solutions (Figure 6). Although the abuse is not "fixable" in a single ED visit, these steps can make a difference and may provide patients the support and resources and confidence they need to increase their safety, well being, and overall health.

\section{Acknowledgments}

Grant support: Dr. Choo is supported by NIDA grant K23DA031881

\section{References}

1. Black, MC.; Basile, KC.; Breiding, MJ., et al. The National Intimate Partner and Sexual Violence Survey (NISVS): 2010 Summary Report. Atlanta, GA: National Center for Injury Prevention and Control, Centers for Disease Control and Prevention; 2011. Available at: http://www.cdc.gov/ ViolencePrevention/pdf/NISVS_Report2010-a.pdf

2. ACEP Policy Statement: Domestic Family Violence. 2007. Available at: http://www.acep.org/ Clinical---Practice-Management/Domestic-Family-Violence/?_taxonomyid=117952

3. Moyer VA. Screening for intimate partner violence and abuse of elderly and vulnerable adults: U.S. preventive services task force recommendation statement. Ann Intern Med. 2013; 158(6):47886.10.7326/0003-4819-158-6-201303190-00588 [PubMed: 23338828]

4. Clinical Preventive Services for Women: Closing the Gaps. Institute of Medicine, The National Academies Press; Washington, DC: 2011.

5. Larkin GL, Hyman KB, Mathias SR, D'Amico F, MacLeod BA. Universal screening for intimate partner violence in the emergency department: importance of patient and provider factors. Ann Emerg Med. 1999; 33(6):669-75. Available at: http://www.ncbi.nlm.nih.gov/pubmed/10339682. [PubMed: 10339682]

6. Rhodes KV, Frankel RM, Levinthal N, Prenoveau E, Bailey J, Levinson W. "You're not a victim of domestic violence, are you?" Provider patient communication about domestic violence. Ann Intern Med. 2007; 147(9):620-7. Available at: http://www.pubmedcentral.nih.gov/articlerender.fcgi? artid=2365713\&tool=pmcentrez\&rendertype=abstract. [PubMed: 17975184 ]

7. Klevens J, Kee R, Trick W, et al. Effect of screening for partner violence on women's quality of life: a randomized controlled trial. JAMA. 2012; 308(7):681-9.10.1001/jama.2012.6434 [PubMed: 22893165]

8. Houry D, Feldhaus K, Peery B, et al. A positive domestic violence screen predicts future domestic violence. J Interpers Violence. 2004; 19(9):955-66.10.1177/0886260504267999 [PubMed: 15296611]

9. Rabin RF, Jennings JM, Campbell JC, Bair-Merritt MH. Intimate partner violence screening tools: a systematic review. Am J Prev Med. 2009; 36(5):439-445.e4.10.1016/j.amepre.2009.01.024 [PubMed: 19362697]

10. Basile, K.; Hertz, M.; Back, S. Intimate Partner Violence and Sexual Violence Victimization Assessment Instruments for Use in Healthcare Settings. Centers for Disease Control and Prevention, National Center for Injury Prevention and Control; Atlanta, GA: 2007.

11. Heron SL, Thompson MP, Jackson E, Kaslow NJ. Do responses to an intimate partner violence screen predict scores on a comprehensive measure of intimate partner violence in low-income 
black women? Ann Emerg Med. 2003; 42(4):483-91.10.1067/S0196064403007182 [PubMed: 14520319]

12. Feldhaus KM, Koziol-McLain J, Amsbury HL, Norton IM, Lowenstein SR, Abbott JT. Accuracy of 3 brief screening questions for detecting partner violence in the emergency department. JAMA. 1997; 277(17):1357-61. Available at: http://www.ncbi.nlm.nih.gov/pubmed/9134940. [PubMed: 9134940]

13. Rhodes KV, Lauderdale DS, He T, Howes DS, Levinson W. "Between me and the computer": increased detection of intimate partner violence using a computer questionnaire. Ann Emerg Med. 2002; 40(5):476-84. Available at: http://www.ncbi.nlm.nih.gov/pubmed/12399790. [PubMed: 12399790]

14. McGrath ME, Bettacchi A, Duffy SJ, Peipert JF, Becker BM, St Angelo L. Violence against women: provider barriers to intervention in emergency departments. Acad Emerg Med. 1997; 4(4): 297-300. Available at: http://www.ncbi.nlm.nih.gov/pubmed/9107329. [PubMed: 9107329]

15. Wu V, Huff $\mathrm{H}$, Bhandari M. Pattern of physical injury associated with intimate partner violence in women presenting to the emergency department: a systematic review and meta-analysis. Trauma Violence Abuse. 2010; 11(2):71-82.10.1177/1524838010367503 [PubMed: 20430799]

16. Choo EK, Nicolaidis C, Jenkinson RH, Cox JM, McConnell KJ. Failure of intimate partner violence screening among patients with substance use disorders. Acad Emerg Med. 2010; 17(8): 886-9.10.1111/j.1553-2712.2010.00817.x [PubMed: 20670328]

17. McFarlane JM, Groff JY, O'Brien JA, Watson K. Secondary prevention of intimate partner violence: a randomized controlled trial. Nurs Res. 2006; 55(1):52-61. Available at: http:// www.ncbi.nlm.nih.gov/pubmed/16439929. [PubMed: 16439929]

18. Lachs M. Editorial Screening for Family Violence: What's an Evidence-Based Doctor To Do? Ann Intern Med. 2004; 140(5):399-400. [PubMed: 14996683]

19. McFarlane J, Parker B, Soeken K, Silva C, Reel S. Safety behaviors of abused women after an intervention during pregnancy. J Obstet Gynecol Neonatal Nurs. 1998; 27(1):64-9. Available at: http://www.ncbi.nlm.nih.gov/pubmed/9475129.

20. Snider C, Webster D, O'Sullivan CS, Campbell J. Intimate partner violence: development of a brief risk assessment for the emergency department. Acad Emerg Med. 2009; 16(11):120816.10.1111/j.1553-2712.2009.00457.x [PubMed: 20053241]

21. Campbell JC, Webster D, Glass N. The danger assessment: validation of a lethality risk assessment instrument for intimate partner femicide. J Interpers Violence. 2009; 24(4):653-74. [PubMed: 18667689]

22. Houry D, Sachs CJ, Feldhaus KM, Linden J. Violence-inflicted injuries: reporting laws in the fifty states. Ann Emerg Med. 2002; 39(1):56-60. Available at: http://www.ncbi.nlm.nih.gov/pubmed/ 11782731. [PubMed: 11782731]

23. Houry D, Kemball RS, Click LA, Kaslow NJ. Development of a brief mental health screen for intimate partner violence victims in the emergency department. Acad Emerg Med. 2007; 14(3): 202-9.10.1197/j.aem.2006.09.056 [PubMed: 17242384]

24. Breiding MJ, Black MC, Ryan GW. Chronic disease and health risk behaviors associated with intimate partner violence-18 U.S. states/territories, 2005. Ann Epidemiol. 2008; 18(7):53844.10.1016/j.annepidem.2008.02.005 [PubMed: 18495490]

25. Narayan U. "Male-Order" Brides: Immigrant Women, Domestic Violence and Immigration Law. Hypatia. 1995; 10(1):104-119.10.1111/j.1527-2001.1995.tb01355.x [PubMed: 11660599]

26. Gonzalez-Guarda RM, Cummings AM, Becerra M, Fernandez MC, Mesa I. Needs and preferences for the prevention of intimate partner violence among Hispanics: a community's perspective. $\mathrm{J}$ Prim Prev. 2013; 34(4):221-35.10.1007/s10935-013-0312-5 [PubMed: 23843106] 


\begin{tabular}{|c|c|c|}
\hline Screening Tool & Questions & Test Performance \\
\hline HITS $^{\mathrm{a}}$ & $\begin{array}{l}\text { How often does your partner: } \\
\text { 1. } \quad \text { Physically hurt you? } \\
\text { 2. } \quad \text { Insult you or talk down to you? } \\
\text { 3. } \quad \text { Threaten you with harm? } \\
\text { 4. } \quad \text { Scream or curse at you? } \\
\end{array}$ & $\begin{array}{l}\text { Sensitivity }^{\mathrm{b}, \mathrm{c}, \mathrm{d}}: 30-88 \% \\
\text { Specificity }^{\mathrm{b}, \mathrm{c}, \mathrm{d}}: 83-97 \%\end{array}$ \\
\hline $\begin{array}{l}\text { Universal Violence Prevention } \\
\text { Screening Protocol (adapted) }^{\mathrm{e}}\end{array}$ & $\begin{array}{l}\text { Have you been in a relationship with a partner } \\
\text { in the past year? } \\
\text { If yes, within the past year has a partner: } \\
\text { (a) Slapped, kicked, pushed, choked, or } \\
\text { punched you? } \\
\text { (b) Forced or coerced you to have sex? } \\
\text { (c) Threatened you with a knife or gun to } \\
\text { scare or hurt you? } \\
\text { (d) Made you afraid that you could be } \\
\text { physically hurt? } \\
\text { (e) Repeatedly used words, yelled, or } \\
\text { screamed in a way that frightened you, } \\
\text { threatened you, put you down, or } \\
\text { made you feel rejected? }\end{array}$ & $\begin{array}{l}\text { PPV for physical violence }{ }^{\mathrm{e}, \mathrm{f}}: 71-89 \% \\
\text { PPV for emotional violence }{ }^{\mathrm{e}, \mathrm{f}}: 75-92 \%\end{array}$ \\
\hline Partner Violence Screen (PVS) ${ }^{g}$ & $\begin{array}{l}\text { 1. Have you been hit, kicked, punched or } \\
\text { otherwise hurt by someone in the past year? If } \\
\text { so, by whom? } \\
\text { 2. Do you feel safe in your current } \\
\text { relationship? } \\
\text { 3. Is there a partner from a previous } \\
\text { relationship who is making you feel unsafe } \\
\text { now? }\end{array}$ & $\begin{array}{l}\text { Sensitivity }{ }^{\mathrm{g}, \mathrm{h}}: 65-71 \% \\
\text { Specificity }^{\mathrm{g}, \mathrm{h}}: 80-84 \%\end{array}$ \\
\hline
\end{tabular}

Figure 1. Examples of Intimate Partner Violence Screening Tools

a. Copyright Kevin Sherin (contact: ksherin@yahoo.com). Permission obtained for reproduction; not to be distributed for commercial use.

b. Chen P-H, Rovi S, Vega M, Jacobs A, Johnson MS. Screening for domestic violence in a predominantly Hispanic clinical setting. Fam Pract. 2005;22(6):61723.

c. Mills TJ, Avegno JL, Haydel MJ. Male victims of partner violence: prevalence and accuracy of screening tools. J Emerg Med. 2006;31(4):447-52.

d. Shakil A, Donald S, Sinacore JM, Krepcho M. Validation of the HITS domestic violence screening tool with males. Fam Med. 2005;37(3):193-8.

e. Heron SL, Thompson MP, Jackson E, Kaslow NJ. Do responses to an intimate partner violence screen predict scores on a comprehensive measure of intimate partner violence in low-income black women? Ann Emerg Med. 2003;42(4):48391.

f. Tested in an urban, ED, black female population; PPV as compared to the Index of Spouse Abuse (ISA)

g. Feldhaus KM, Koziol-McLain J, Amsbury HL, Norton IM, Lowenstein SR, Abbott JT. Accuracy of 3 brief screening questions for detecting partner violence in the emergency department. JAMA;277(17):1357-61.

h. Sensitivity and specificity compared to the ISA. 


\begin{tabular}{|c|c|c|}
\hline Resource & Source & Website / Phone Number \\
\hline $\begin{array}{l}\text { Detailed information about a variety of } \\
\text { IPV screening instruments }\end{array}$ & $\begin{array}{l}\text { Centers for Disease Control and } \\
\text { Prevention (CDC) }\end{array}$ & $\begin{array}{l}\text { http://www.cdc.gov/ncipc/pub- } \\
\text { res/images/ipvandsvscreening.pdf }\end{array}$ \\
\hline $\begin{array}{l}\text { Compendium on state statutes and } \\
\text { policies for mandatory reporting }\end{array}$ & Futures Without Violence & $\begin{array}{l}\text { http:///www.futureswithoutviolence.org/userfiles } \\
\text { /file/HealthCare/Compendium\%20Final.pdf }\end{array}$ \\
\hline $\begin{array}{l}\text { Hotline for information about IPV, } \\
24 / 7 \text { advocates available over the } \\
\text { phone and through online chat to } \\
\text { provide counseling, safety planning } \\
\text { and referrals }\end{array}$ & National Domestic Violence Hotline & $\begin{array}{l}\text { The National Domestic Violence Hotline } \\
\text { http://www.thehotline.org } \\
\text { 1-800-799-7233 }\end{array}$ \\
\hline $\begin{array}{l}\text { Free materials for healthcare providers, } \\
\text { including: physician training materials, } \\
\text { patient brochures and posters, and } \\
\text { safety planning cards. }\end{array}$ & Futures Without Violence & $\begin{array}{l}\text { http://www. futureswithoutviolence.org } \\
\text { (Under "Resources and Events" } \rightarrow \text { "Order } \\
\text { Material") }\end{array}$ \\
\hline
\end{tabular}

Figure 2. Resources for Managing IPV in the Emergency Department 


\begin{tabular}{|l|l|}
\hline $\begin{array}{l}\text { Informing patients about } \\
\text { confidentialty }\end{array}$ & $\begin{array}{l}\text { "I want you to know that everything here is confidential, meaning } \\
\text { that I won't talk to anyone else about what is said unless you tell me } \\
\text { that you intend to harm yourself or others, or **" (fill in state- } \\
\text { specific statutes)." }\end{array}$ \\
\hline Normalizing statement & $\begin{array}{l}\text { "We (I) like to ask all our (my) patients about their relationships } \\
\text { because it can affect your health." }\end{array}$ \\
\hline $\begin{array}{l}\text { Immediate response to } \\
\text { positive screen }\end{array}$ & "You said your partner is harming you. Tell me more." \\
\hline Validation statements & $\begin{array}{l}\text { "It takes courage to talk about your abuse with me today." } \\
\text { "I want you to know that you are not alone. There are many others } \\
\text { going through this, and I am here to listen and to help." "What you } \\
\text { are experiencing is called abuse, and it is not your fault." }\end{array}$ \\
\hline
\end{tabular}

Figure 3. Suggested Language for Screening and Discussing IPV 
Has the physical violence increased in frequency or severity over the past 6 months?

Has your partner ever used a weapon or threatened you with a weapon?

Do you believe your partner is capable of killing you?

Have you ever been beaten by your partner while you were pregnant?

Is your partner violently and constantly jealous of you?

Figure 4. Brief Risk Assessment*

*From Snider C, Webster D, O'Sullivan CS, Campbell J. Intimate partner violence:

development of a brief risk assessment for the emergency department. Acad Emerg Med;

16(11):1208-16. 
If you are still in the relationship:

- Think of a safe place to go if an argument occurs - avoid rooms with no exits (bathroom), or rooms with weapons (kitchen).

- Think about and make a list of safe people to contact.

- Keep change with you at all times.

- Memorize all important numbers.

- Establish a "code word" or "sign" so that family, friends, teachers or co-workers know when to call for help.

- Establish a code word or sign with your children that will tell them call for help and/or leave the house immediately

- Think about what you will say to your partner if helshe becomes violent.

Remember, you have the right to live without fear and violence.

If you have left the relationship:

- Change your phone number.

- Screen calls.

- Save and document all contacts, messages, injuries or other incidents involving the batterer.

- Change locks, if the batterer has a key.

- Avoid staying alone.

- Plan how to get away if confronted by an abusive partner.

- If you have to meet your partner, do it in a public place.

- Vary your routine.

- Notify school and work contacts.

- Call a shelter for battered women.

If you leave the relationship or are thinking of leaving, you should take important papers and documents with you to enable you to apply for benefits or take legal action.

Important papers you should take include:

- Social security cards and birth certificates for you and your children

- Marriage license

- Leases or deeds in your name or both yours and your partner's names

- Checkbook

- Credit cards

- Bank and charge account statements

- Insurance policies

- Proof of income for you and your spouse (pay stubs or W-2's)

- Any documentation of past incidents of abuse (photos, police reports, medical records, etc.)

Figure 5. Recommended Safety Behaviors ${ }^{a}$

a) Adapted from the National Coalition Against Domestic Violence (http://www.ncadv.org/ protectyourself/SafetyPlan.php) 


\begin{tabular}{|l|l|}
\hline Potential Obstacles & Potential Solution \\
\hline $\begin{array}{l}\text { Difficult to perform screening } \\
\text { routinely and consistently }\end{array}$ & $\begin{array}{l}\text { Implement IPV screening into triage workflow } \\
\text { and/or EMR. }\end{array}$ \\
\hline $\begin{array}{l}\text { Providers uncertain about how to } \\
\text { respond to positive screens }\end{array}$ & $\begin{array}{l}\text { Access free online physician training materials (see } \\
\text { Figure 2). }\end{array}$ \\
\hline $\begin{array}{l}\text { IPV screening practices may erode } \\
\text { over time }\end{array}$ & $\begin{array}{l}\text { Implement quality review and provide regular } \\
\text { training to maintain knowledge and skills. }\end{array}$ \\
\hline $\begin{array}{l}\text { Screening on arrival may be } \\
\text { difficult or impossible due to } \\
\text { illness or intoxication }\end{array}$ & $\begin{array}{l}\text { Create system prompts to perform screening later in } \\
\text { the visit when patient is able to participate. }\end{array}$ \\
\hline $\begin{array}{l}\text { Providers may not have the } \\
\text { knowledge base to provide } \\
\text { instruction on safety behaviors and } \\
\text { other needed resources. }\end{array}$ & $\begin{array}{l}\text { Use safety brochures or cards to aid discussions; } \\
\text { provide referrals to hotlines and domestic violence } \\
\text { agencies for counseling and in-depth on a broad } \\
\text { array of related services. }\end{array}$ \\
\hline
\end{tabular}

Figure 6. Addressing Obstacles to IPV Screening Management 